\title{
Hypoglycemic and Hypolipidemic Effects of Ethanolic Extract of Mirabilis jalapa L. Root on Normal and Diabetic Mice
}

\author{
Ji-Yin Zhou, ${ }^{1}$ Shi-Wen Zhou, ${ }^{1}$ Sheng-Ya Zeng, ${ }^{1}$ Jian-Yun Zhou, ${ }^{2}$ \\ Ming-Jin Jiang, ${ }^{1}$ and Yan $\mathrm{He}^{1}$ \\ ${ }^{1}$ Base for Drug Clinical Trial, Xinqiao Hospital, Third Military Medical University, Chongqing 400037, China \\ ${ }^{2}$ Research Division, Xinqiao Hospital, Third Military Medical University, Chongqing 400037, China
}

Correspondence should be addressed to Shi-Wen Zhou, zhoushiwen2007@yahoo.com

Received 6 August 2011; Revised 22 October 2011; Accepted 16 November 2011

Academic Editor: Bhushan Patwardhan

Copyright ( 2012 Ji-Yin Zhou et al. This is an open access article distributed under the Creative Commons Attribution License, which permits unrestricted use, distribution, and reproduction in any medium, provided the original work is properly cited.

The present study investigated the insulin sensitivity, hypoglycemic, and hypolipidemic activities of ethanolic extract of Mirabilis jalapa L. root (EEM) in normal and diabetic mice. After induction of diabetes with streptozotocin, both normal and diabetic mice were singly or repeatedly for 28 days administrated with EEM at doses of 2, 4, $8 \mathrm{~g} / \mathrm{kg}$, respectively. Before induction of diabetes, mice were administrated with EEM at doses of 2, 4, $8 \mathrm{~g} / \mathrm{kg}$ for 14 days and were injected with streptozotocin and continued on EEM administration for another 28 days. Both after and before induction of diabetes, repeated administration with $4,8 \mathrm{~g} / \mathrm{kg}$ EEM continually lowered blood glucose level, decreased serum insulin level and improved insulin sensitivity index, and lowered serum total cholesterol, triglyceride levels and triglyceride content in liver and skeletal muscle, and increased glycogen content in these tissues; but repeated administration had no influence on those indexes of normal mice. Single administration with EEM $(4,8 \mathrm{~g} / \mathrm{kg})$ showed hypoglycemic effect in oral glucose tolerance test in normal and diabetic mice. Single administration with EEM had no hypoglycemic and hypolipidemic effects on normal and diabetic mice. These results suggest that EEM possesses both potential insulin sensitivity, hypoglycemic, and hypolipidemic effects on diabetes.

\section{Introduction}

Type 2 diabetes mellitus, a metabolic disorder with manifestations of hyperglycemia and hyperinsulinemia, is one of the commonest chronic diseases worldwide [1]. Though different types of oral hypoglycemic agents are available for the treatment of diabetes mellitus, there is increasing demand by patients to use antidiabetic natural products because of the undesirable side effects of the existing drugs. In many countries, much attention has been paid to find novel type of natural antidiabetic drugs from various medicinal plants [2-5]. With thousands of years of medical practice, a great deal of valuable experience has been accumulated in traditional Chinese medical system for diabetic therapy and several herbs have been used to improve the hyperglycemic condition in diabetic patients. Because of their effectiveness, limited side effects, and relatively low cost, herbal drugs are widely prescribed even when their biologically active compounds are unknown [6].
Mirabilis jalapa L. belongs to the family Nyctaginaceae and is known as "four o'clock," "maravilha," "belle de nuit," "buenas tardes," "dondiego de noche," "jalap," "noche buena," or "Tzu Mo Li" in different areas. Mirabilis jalapa L. is widely used to treat dysentery, diarrhea, muscular pain, and abdominal colics in different countries [7-9], and its extract has antibacterial, antiviral, and antifungal functions [10-12]. In China, Mirabilis jalapa L. is widely distributed and commonly used with its root and has been used as traditional Chinese medicine and ethnic drug to treat diabetes [13, 14], constipation [15], genitourinary system disorders, and injuries [16]. Mirabilis jalapa L. root contains alkaloids, glycosides, carbohydrates, and phytosterols by phytochemical analysis $[9,17]$. According to literatures, trigonelline is one of the components of Mirabilis jalapa $\mathrm{L}$. root [18]. Trigonelline has been shown to reduce blood glucose concentrations in rats $[19,20]$ and in human $[21,22]$. Only recently, Piyali et al. [17] reported the hypoglycemic 
and hypolipidemic effects of Mirabilis jalapa L. root on streptozotocin-induced diabetic Wistar albino rats.

In this study, the experiments were designed to detect the insulin sensitivity and hypoglycemic and hypolipidemic activities of ethanolic extract of Mirabilis jalapa L. root (EEM) on both diabetic and normal mice after induction with streptozotocin with both singly and repeatedly administration, and on diabetes before induction with repeatedly administration, and compared with glibenclamide as a reference standard. Oral glucose tolerance test was also measured on normal and diabetic mice after single EEM administration.

\section{Materials and Methods}

2.1. Plant Material and EEM Preparation. The root of Mirabilis jalapa L. was collected from Chongqing city of China. They were taxonomically authenticated by Dr. Guo-yue Zhong, and a voucher specimen of the plant (TRI7374) has been deposited in Chongqing Academy of Chinese Materia Medica.

The root was dried in shade and powdered in a grinder. For the preparation of EEM, dried powder of Mirabilis jalapa L. root $(2 \mathrm{~kg}$ ) was refluxed with 10 volumes of $70 \%$ ethanol three times, one hour for each time. The combined ethanolic extract was filtered using a Millipore filter (Millipore $0.2 \mathrm{~mm}$, St. Quentin en Yvelines, France) to remove particulate matter. The ethanolic extract was concentrated and dried into solid residues in vacuo $(95.08 \mathrm{mg}$ extract/g crude material). The residue was stored at $4^{\circ} \mathrm{C}$, and the desired dose ( $\mathrm{g}$ of Mirabilis jalapa L. root of per $\mathrm{kg}$ body weight) was reconstituted in distilled water daily, just before administration.

Mirabilis jalapa L. root has recently been studied for its chemical composition by Piyali et al. [17]. The aqueous extract had the highest $(3.09 \%)$ extractive value, and the ethyl acetate extract had the lowest $(0.13 \%)$ extractive value. The petroleum ether extract contained alkaloids, and benzene and chloroform extracts both contained glycosides, phytosterols; acetone extract contained alkaloids, carbohydrates; ethyl acetate extract contained alkaloid, carbohydrates, and glycoside; methanol, ethanol, and water extracts all contained alkaloids, carbohydrates, and phytosterols.

2.2. Preliminary Phytochemical Analysis. High performance liquid chromatography method has been developed for the analysis of trigonelline in Mirabilis jalapa L. root [18]. High-performance liquid chromatography analysis was performed on a YWG-C18 column $(250 \times 4.6 \mathrm{~mm}, 10 \mu \mathrm{m})$; mobile phases: acetonitrile water $(80: 20, \mathrm{v} / \mathrm{v})$; flow rate: $0.8 \mathrm{~mL} / \mathrm{min}$. Peaks were analyzed spectroscopically at $265 \mathrm{~nm}$ with a UV-visible-light detector. The EEM solutions were quantified by spiking with a known amount of standard (trigonelline) and also by comparing the area under curve. The repeatability of the method was evaluated by injecting the solution of EEM and standard solution for three times, and the relative standard deviation percentage was calculated.
2.3. Animals and Drugs. Male KM mice (18-22 g) were purchased from Third Military Medical University, China. The animals were given a standard pellet diet and water ad libitum and were maintained under standard environmental conditions $\left(20 \pm 2{ }^{\circ} \mathrm{C}, 12 \mathrm{~h}\right.$ of light/dark cycle). Streptozotocin was purchased from Sigma Co. Ltd, St. Louis, MO, USA. Glibenclamide (no. 20100224, purity 99.56\%) and metformin hydrochloride (no. 20110809, purity 99.60\%) were purchased from Wuhan Yuancheng Technology Development Co. Ltd, China. Insulin radioimmunoassay kit was provided by Beijing North Institute of Biological Technology, China. All other chemicals were obtained from local sources and were analytical grade. Throughout the test, experimental mice were processed in accordance with the UK Animals (Scientific Procedures) Act 1986 and associated guidelines.

2.4. Study of EEM on Normal Mice. Sixteen-hour-fasted normal mice were both randomly assigned to five different groups ( $n=10$ in each group). The normal control group received distilled water, and normal treated groups received glibenclamide at a dose of $0.76 \mathrm{mg} / \mathrm{kg}$ and EEM at doses of 2,4 , and $8 \mathrm{~g} / \mathrm{kg}$, respectively. The selected doses of EEM were according to the literature [13].

Single administration procedure is as follows: the drug solutions or distilled water were administered orally $0.2 \mathrm{~mL} / 10 \mathrm{~g}$ body weight by gastric intubation using a syringe once daily at 9:00 a.m. Two hours after a single administration, mice were anaesthetized, and the eye socket blood of mouse was collected for measurement of blood glucose level with a portable glucometer (OneTouch SureStep Meter, LifeScan Company, USA), serum insulin, and total cholesterol (TC) and triglyceride (TG) levels. The liver and skeletal muscle were removed and immediately frozen in liquid nitrogen.

The repeated administration procedure is as follows: mice were treated as single administration once daily for 28 days. Body weights were weighed every two weeks. At 14th day, 16-hour-fasted blood sample was collected from the tail for blood glucose measurement. At 28th day, mice were anaesthetized and 16-hour-fasted eye socket blood of mouse was collected for measurement of blood glucose, serum insulin, and TC and TG levels. The liver and skeletal muscle were also collected and frozen in liquid nitrogen.

2.5. Study of EEM on Diabetic Mice. The animals were fasted for $16 \mathrm{~h}$ prior to the induction of diabetes. Streptozotocin was freshly prepared in $0.1 \mathrm{~mol} / \mathrm{L}$ citrate buffer solution ( $\mathrm{pH} 4.5)$ and was intraperitoneally injected to mice with a single dose of $60 \mathrm{mg} / \mathrm{kg}$. After three days, 16-hour-fasted blood sample was collected from the tail for measurement of fasting blood glucose level. Mice with fasting blood glucose level higher than $11.1 \mathrm{mmol} / \mathrm{L}$ were considered diabetic ones and were randomly divided into five different groups $(n=10$ in each group). The diabetic control group received distilled water, and diabetic treated groups received glibenclamide at a dose of $0.76 \mathrm{mg} / \mathrm{kg}$ and EEM at doses of 2, 4, and $8 \mathrm{~g} / \mathrm{kg}$, respectively. The single and repeated administration procedures were the same as in Subsection 2.4. 
2.6. Oral Glucose Tolerance Test. Prior to an oral glucose tolerance test, both normal and diabetic mice induced by the above-mentioned method with fasting blood glucose level higher than $11.1 \mathrm{mmol} / \mathrm{L}$ were fasted for $16 \mathrm{~h}$. Distilled water (control), two reference drugs, glibenclamide $(2.5 \mathrm{mg} / \mathrm{kg})$ and metformin $(50 \mathrm{mg} / \mathrm{kg})$, and three doses of EEM (2, 4 , and $8 \mathrm{~g} / \mathrm{kg}$ ) were orally administered to groups of 10 mice each. Two hours later, glucose $(2.0 \mathrm{~g} / \mathrm{kg})$ was orally administrated to each mouse. Blood samples were taken from tail vein at 0 (just before the glucose administration), $15,30,60$, and $120 \mathrm{~min}$ for the assay of glucose.

2.7. Measurement of Insulin Level in Serum. Serum insulin concentration was measured by commercial kits according to the manufacturer's instructions. Insulin sensitivity index $($ ISI $)=\log (1 /$ fasting plasma glucose $\times$ serum insulin $)$.

2.8. Measurement of TC and TG Levels in Blood. TC and TG levels were determined by spectrophotometry with commercial kit provided by Nanjing Jiancheng Bioengineering Institute, China.

2.9. Measurement of Glycogen and TG Contents in Liver and Skeletal Muscle. Glycogen content was determined by spectrophotometry with commercial kit provided by Nanjing Jiancheng Bioengineering Institute, China. TG content in liver and skeletal muscle was measured by the method of $\mathrm{Hu}$ et al. [23]. The frozen liver $(3-5 \mathrm{mg})$ and skeletal muscle (15-20 mg) were used for TG extraction. Each frozen tissue was added to $0.3 \mathrm{~mL}$ heptane-isopropanol-tween mixture $(3: 2: 0.01$ by volume) and homogenized. This homogenate was centrifuged at $1500 \times g$ at $4^{\circ} \mathrm{C}$ for $15 \mathrm{~min}$. Supernatants (upper phase contained extracted TG) were collected and evaporated with vacuum centrifuge. The TG content was determined by spectrophotometry with commercial kit (Nanjing Jiancheng Bioengineering Institute, China).

2.10. Statistical Analyses. All data were expressed as mean \pm SD. Statistical analysis was performed with one-way ANOVA followed by Tukey post hoc test for multiple comparisons. $P<0.05$ was considered significant.

\section{Results}

3.1. Phytochemical Study of EEM. Phytochemical study of EEM confirmed the presence of trigonelline. The content and variety of trigonelline which has a maximum absorbance at $256 \mathrm{~nm}$ is $0.1818 \pm 0.0109 \mathrm{mg} / \mathrm{g}$ Mirabilis jalapa L. root (Figure 1).

3.2. Effects of EEM on Blood Glucose Level of Single Administration. In streptozotocin-induced untreated diabetic mice, fasting blood glucose level was significantly higher than that of untreated normal ones both before and after EEM administration $(P<0.01)$. But fasting blood glucose level did not change after single administration of EEM at doses of 2, 4 , and $8 \mathrm{~g} / \mathrm{kg}$ either in normal or diabetic mice (Figure 2(a)). In the diabetic mice, glibenclamide produced significant hypoglycemic effect. But glibenclamide had no effect on glucose level of normal mice.

3.3. Effects of EEM on Blood Glucose Level of Repeated Administration. Changes of blood glucose level after repeated EEM and glibenclamide administration in normal and diabetic mice were shown in Figure 2(b). In normal mice, both 14 and 28 days of all repeated doses $(2,4$, and $8 \mathrm{~g} / \mathrm{kg}$ ) of EEM and glibenclamide $(0.76 \mathrm{mg} / \mathrm{kg})$ administration caused no significant reduction in blood glucose level. Both compared to before administration and untreated diabetic mice, reduction in blood glucose level was observed after 14 days of repeated administration of $4,8 \mathrm{~g} / \mathrm{kg}$ EEM and glibenclamide to diabetic ones $(P<0.01)$. Progressive reduction was observed after 28 days of repeated $4,8 \mathrm{~g} / \mathrm{kg}$ EEM administration $(P<0.01)$. Both 14 and 28 days of $2 \mathrm{~g} / \mathrm{kg}$ EEM administration resulted in no reduction in blood glucose level. Oppositely, the blood glucose level of untreated diabetic mice was continually increased during the experimental period.

3.4. Effects of EEM on Serum Insulin Level and ISI of Single Administration. Significant increased serum insulin level but decreased ISI were in diabetic mice $(P<0.01)$ when compared to untreated normal mice. Two hours after single administration of all doses of 2, 4, and $8 \mathrm{~g} / \mathrm{kg}$ EEM and glibenclamide failed to reduce serum insulin level and to improve ISI both in normal and diabetic mice Table 1.

3.5. Effects of EEM on Serum Insulin Level and ISI of Repeated Administration. As showed in Table 1, in normal mice, daily administrations of 2, 4, and $8 \mathrm{~g} / \mathrm{kg}$ EEM and glibenclamide over 28 days had no effect on serum insulin level and ISI. In diabetic mice, 28 days administration of $4,8 \mathrm{~g} / \mathrm{kg}$ EEM reduced serum insulin level and improved ISI when compared to untreated diabetic mice $(P<0.01)$. But 28 day administration of $2 \mathrm{~g} / \mathrm{kg}$ EEM and glibenclamide had no effect on serum insulin level and ISI.

3.6. Effects of EEM on Serum TC and TG Levels of Single Administration. Streptozotocin injection caused significant increases in serum TC and TG levels $(P<0.01)$ when compared to untreated normal mice. Two hours after single administration of all doses of 2, 4, and $8 \mathrm{~g} / \mathrm{kg}$ EEM and glibenclamide failed to reduce serum TC and TG levels both in normal and diabetic mice (Table 2).

\subsection{Effects of EEM on Serum TC and TG Levels of Repeated} Administration. Changes of serum TC and TG levels in normal and diabetic mice during 28 days of repeated EEM and glibenclamide administration were shown in Table 2. In normal mice, daily administrations of 2,4 , and $8 \mathrm{~g} / \mathrm{kg}$ EEM and glibenclamide over 28 days had no effect on TC and TG levels. In diabetic mice, 28 days administration of $2 \mathrm{~g} / \mathrm{kg}$ EEM and glibenclamide did not produce any significant change in TC and TG levels. However, 28 days administration of 4 , $8 \mathrm{~g} / \mathrm{kg}$ EEM reduced TC and TG levels when compared to untreated diabetic mice $(P<0.01)$. 


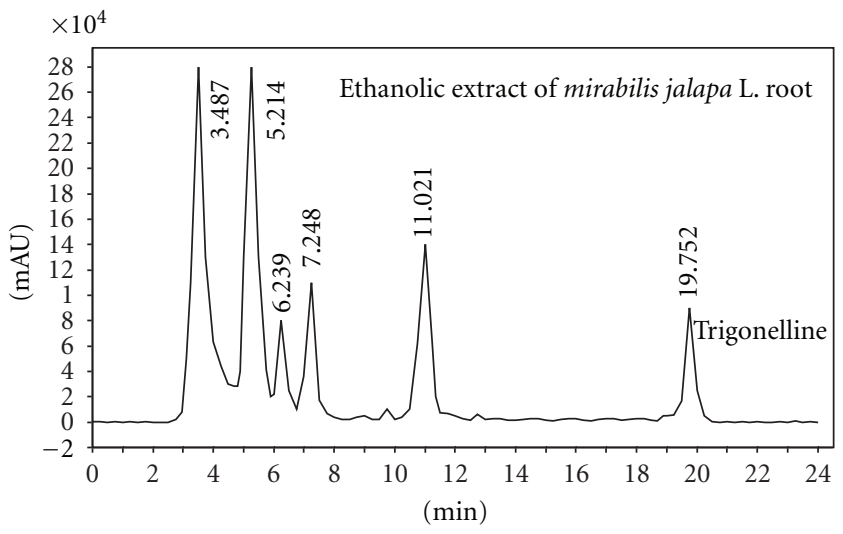

(a)

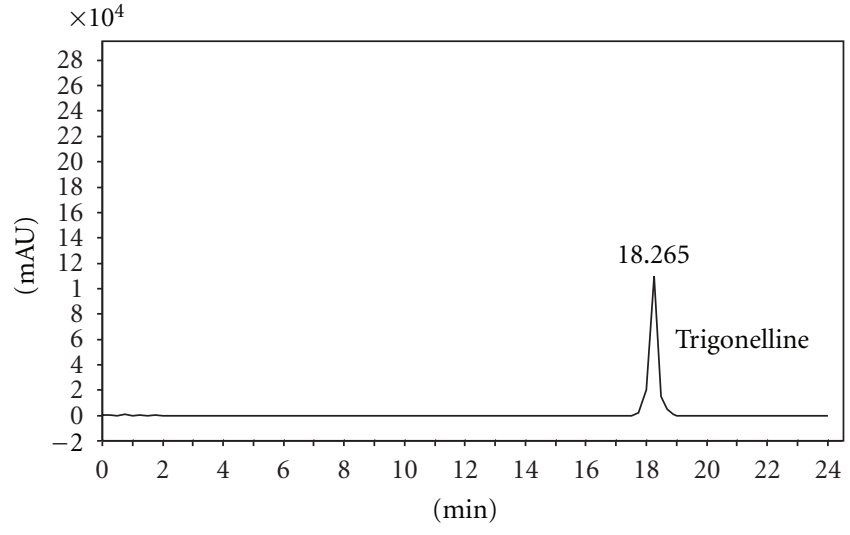

(b)

FIGURE 1: Representative high-performance liquid chromatography chromatograms of EEM and trigonelline $\left(R_{t}=19.725\right)$.

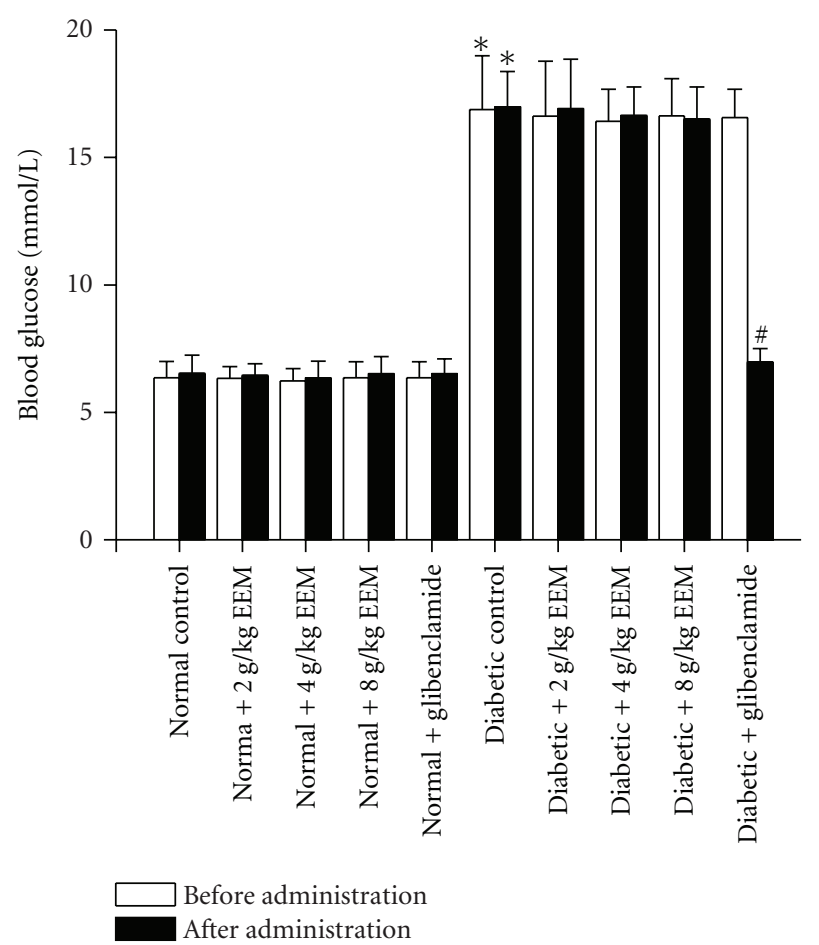

(a)

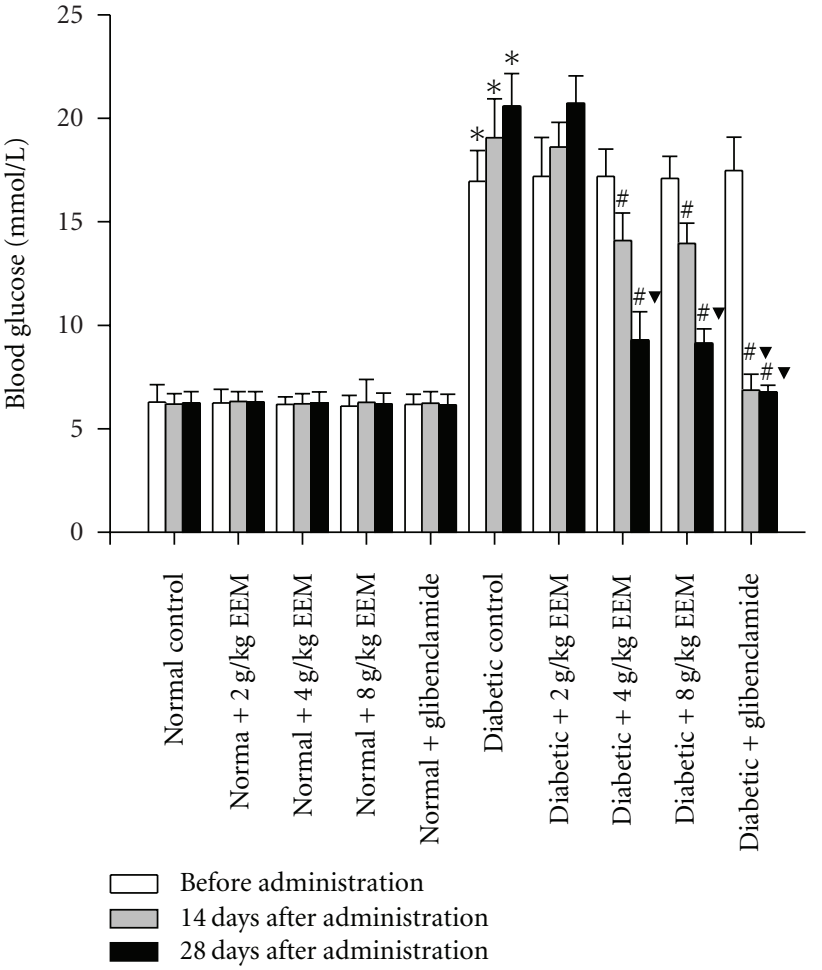

(b)

FIGURE 2: Effects of single and repeated EEM administration on blood glucose level in normal and diabetic mice. Data are expressed as mean $\pm \mathrm{SD}, n=10$ mice per group. ${ }^{*} P<0.01$, compared to normal control. ${ }^{\#} P<0.01$, compared to diabetic control. ${ }^{t} P<0.01$, compared to before administration.

3.8. Effects of EEM on Glycogen and TG Contents in Liver and Skeletal Muscle of Single Administration. Changes of glycogen and TG contents in liver and skeletal muscle of normal and diabetic mice after single administration of EEM and glibenclamide were shown in Table 3. In normal mice, single administrations of 2, 4, and $8 \mathrm{~g} / \mathrm{kg}$ EEM and glibenclamide had no effect on glycogen and TG contents in liver and skeletal muscle. In diabetic mice, streptozotocin injection caused significant increase in TG level and decrease in glycogen level when compared to untreated normal mice $(P<0.01)$. Single administration of 2,4 , and $8 \mathrm{~g} / \mathrm{kg}$ EEM and glibenclamide also did not produce any significant change in glycogen and TG contents in liver and skeletal muscle in diabetic mice.

3.9. Effects of EEM on Glycogen and TG Contents in Liver and Skeletal Muscle of Repeated Administration. Changes of glycogen and TG contents in liver and skeletal muscle 


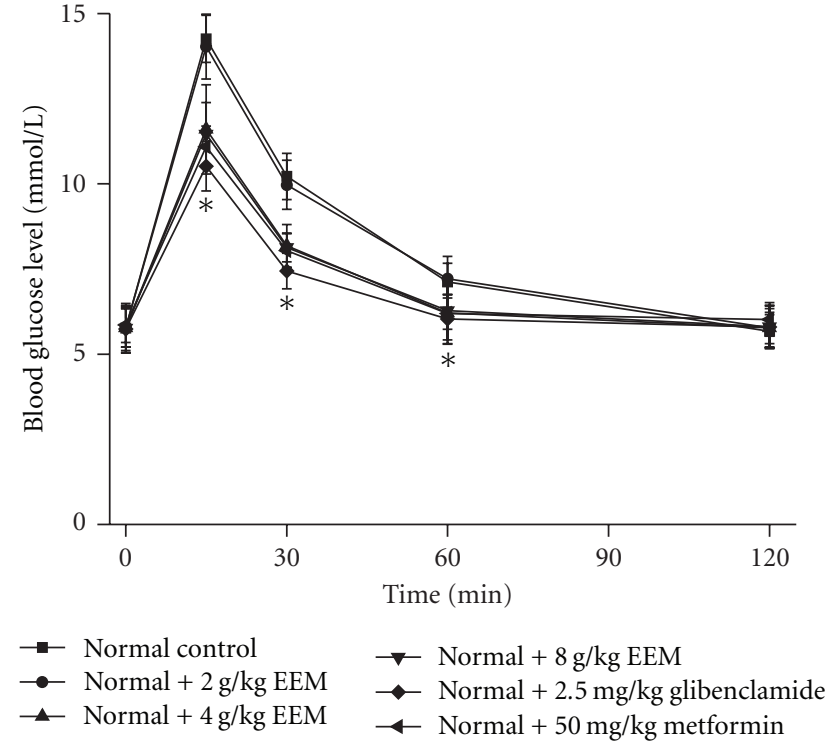

(a)

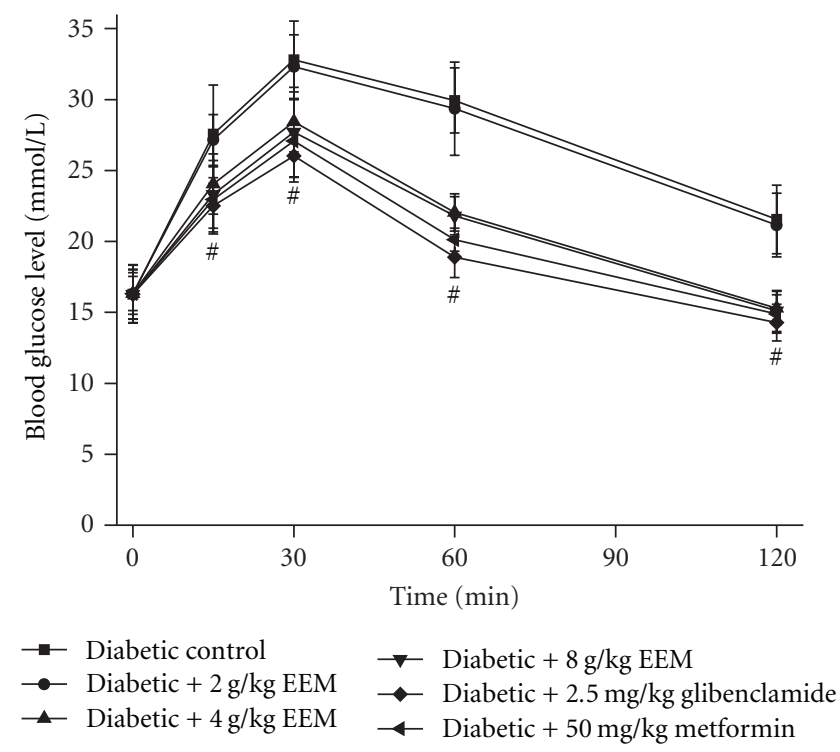

(b)

FIgURE 3: Effects of EEM on oral glucose tolerance test in normal and diabetic mice. Data are expressed as mean \pm SD, $n=10$ mice per group. ${ }^{*} P<0.01$, compared to normal control. ${ }^{\#} P<0.01$, compared to diabetic control.

TABLE 1: Effects of single and repeated EEM administration on serum insulin level and ISI in normal and diabetic mice.

\begin{tabular}{|c|c|c|c|c|}
\hline \multirow{2}{*}{ Group } & \multicolumn{2}{|c|}{ Single administration } & \multicolumn{2}{|c|}{ Repeated administration } \\
\hline & Serum insulin $(\mathrm{mU} / \mathrm{L})$ & ISI & Serum insulin (mU/L) & ISI \\
\hline Normal control & $11.80 \pm 0.83$ & $-1.88 \pm 0.06$ & $11.49 \pm 1.17$ & $-1.85 \pm 0.04$ \\
\hline Normal + $2 \mathrm{~g} / \mathrm{kg}$ EEM & $11.65 \pm 0.44$ & $-1.88 \pm 0.04$ & $11.68 \pm 0.60$ & $-1.87 \pm 0.04$ \\
\hline Normal + $4 \mathrm{~g} / \mathrm{kg}$ EEM & $11.60 \pm 0.79$ & $-1.86 \pm 0.06$ & $11.55 \pm 0.63$ & $-1.86 \pm 0.05$ \\
\hline Normal $+8 \mathrm{~g} / \mathrm{kg}$ EEM & $11.06 \pm 0.30$ & $-1.86 \pm 0.05$ & $11.67 \pm 0.64$ & $-1.86 \pm 0.05$ \\
\hline Normal + glibenclamide & $11.91 \pm 0.36$ & $-1.89 \pm 0.04$ & $11.54 \pm 0.75$ & $-1.85 \pm 0.06$ \\
\hline Diabetic control & $16.74 \pm 0.53^{*}$ & $-2.45 \pm 0.05^{*}$ & $14.81 \pm 1.04^{*}$ & $-2.48 \pm 0.05^{*}$ \\
\hline Diabetic $+2 \mathrm{~g} / \mathrm{kg}$ EEM & $16.43 \pm 0.43$ & $-2.44 \pm 0.05$ & $14.65 \pm 1.88$ & $-2.48 \pm 0.08$ \\
\hline Diabetic $+4 \mathrm{~g} / \mathrm{kg}$ EEM & $16.01 \pm 0.53$ & $-2.43 \pm 0.03$ & $11.88 \pm 0.90$ & $-2.04 \pm 0.08^{\#}$ \\
\hline Diabetic $+8 \mathrm{~g} / \mathrm{kg}$ EEM & $16.07 \pm 0.95$ & $-2.42 \pm 0.04$ & $11.68 \pm 0.81$ & $-2.03 \pm 0.05^{\#}$ \\
\hline Diabetic + glibenclamide & $36.83 \pm 4.82^{\#}$ & $-2.40 \pm 0.09$ & $39.15 \pm 6.55^{\#}$ & $-2.42 \pm 0.09$ \\
\hline
\end{tabular}

Insulin sensitivity index $($ ISI $)=\log (1 /$ fasting plasma glucose $\times$ serum insulin $)$. Data are expressed as mean $\pm \mathrm{SD}, n=10$ mice per group. $* P<0.01$ when compared to normal control. ${ }^{\#} P<0.01$ when compared to diabetic control.

TABLE 2: Effects of single and repeated EEM administration on serum TC and TG levels in normal and diabetic mice.

\begin{tabular}{|c|c|c|c|c|}
\hline \multirow{2}{*}{ Group } & \multicolumn{2}{|c|}{ Single administration } & \multicolumn{2}{|c|}{ Repeated administration } \\
\hline & $\mathrm{TC}(\mathrm{mmol} / \mathrm{L})$ & $\mathrm{TG}(\mathrm{mmol} / \mathrm{L})$ & $\mathrm{TC}(\mathrm{mmol} / \mathrm{L})$ & $\mathrm{TG}(\mathrm{mmol} / \mathrm{L})$ \\
\hline Normal control & $2.13 \pm 0.20$ & $0.74 \pm 0.07$ & $2.13 \pm 0.16$ & $0.75 \pm 0.06$ \\
\hline Normal + $2 \mathrm{~g} / \mathrm{kg}$ EEM & $2.11 \pm 0.20$ & $0.75 \pm 0.11$ & $2.14 \pm 0.17$ & $0.75 \pm 0.06$ \\
\hline Normal + $4 \mathrm{~g} / \mathrm{kg}$ EEM & $2.17 \pm 0.22$ & $0.77 \pm 0.09$ & $2.14 \pm 0.20$ & $0.74 \pm 0.05$ \\
\hline Normal + 8 g/kg EEM & $2.08 \pm 0.22$ & $0.75 \pm 0.08$ & $2.10 \pm 0.16$ & $0.73 \pm 0.06$ \\
\hline Normal + glibenclamide & $2.11 \pm 0.21$ & $0.75 \pm 0.08$ & $2.11 \pm 0.14$ & $0.74 \pm 0.08$ \\
\hline Diabetic control & $3.47 \pm 0.33^{*}$ & $1.26 \pm 0.12^{*}$ & $3.49 \pm 0.32 *$ & $1.28 \pm 0.09^{*}$ \\
\hline Diabetic $+2 \mathrm{~g} / \mathrm{kg}$ EEM & $3.45 \pm 0.39$ & $1.24 \pm 0.10$ & $3.47 \pm 0.26$ & $1.24 \pm 0.11$ \\
\hline Diabetic $+4 \mathrm{~g} / \mathrm{kg}$ EEM & $3.44 \pm 0.43$ & $1.24 \pm 0.12$ & $2.92 \pm 0.22^{\#}$ & $1.01 \pm 0.11^{\#}$ \\
\hline Diabetic $+8 \mathrm{~g} / \mathrm{kg}$ EEM & $3.44 \pm 0.31$ & $1.25 \pm 0.10$ & $2.82 \pm 0.25^{\#}$ & $0.97 \pm 0.07^{\#}$ \\
\hline Diabetic + glibenclamide & $3.48 \pm 0.34$ & $1.23 \pm 0.10$ & $3.46 \pm 0.13$ & $1.27 \pm 0.09$ \\
\hline
\end{tabular}

Data are expressed as mean $\pm \mathrm{SD}, n=10$ mice per group. ${ }^{*} P<0.01$ when compared to normal control. ${ }^{\#} P<0.01$ when compared to diabetic control. 
TABLE 3: Effects of single EEM administration on glycogen and TG contents in liver and skeletal muscle of normal and diabetic mice.

\begin{tabular}{|c|c|c|c|c|}
\hline \multirow{2}{*}{ Group } & \multicolumn{2}{|c|}{ Liver } & \multicolumn{2}{|c|}{ Skeletal muscle } \\
\hline & Glycogen (mg/g) & $\mathrm{TG}(\mu \mathrm{mol} / \mathrm{g})$ & Glycogen $(\mathrm{mg} / \mathrm{g})$ & $\mathrm{TG}(\mu \mathrm{mol} / \mathrm{g})$ \\
\hline Normal control & $12.73 \pm 0.89$ & $3.40 \pm 0.22$ & $1.69 \pm 0.16$ & $0.116 \pm 0.005$ \\
\hline Normal + $2 \mathrm{~g} / \mathrm{kg}$ EEM & $12.58 \pm 0.91$ & $3.40 \pm 0.20$ & $1.67 \pm 0.12$ & $0.115 \pm 0.005$ \\
\hline Normal $+4 \mathrm{~g} / \mathrm{kg}$ EEM & $12.46 \pm 0.74$ & $3.47 \pm 0.29$ & $1.65 \pm 0.06$ & $0.117 \pm 0.006$ \\
\hline Normal + 8 g/kg EEM & $12.57 \pm 0.96$ & $3.44 \pm 0.31$ & $1.69 \pm 0.12$ & $0.115 \pm 0.007$ \\
\hline Normal + glibenclamide & $12.66 \pm 0.96$ & $3.40 \pm 0.35$ & $1.68 \pm 0.15$ & $0.111 \pm 0.010$ \\
\hline Diabetic control & $6.77 \pm 0.55^{*}$ & $5.17 \pm 0.26^{*}$ & $2.89 \pm 0.20^{*}$ & $0.215 \pm 0.017^{*}$ \\
\hline Diabetic $+2 \mathrm{~g} / \mathrm{kg}$ EEM & $6.99 \pm 0.60$ & $5.27 \pm 0.48$ & $2.89 \pm 0.21$ & $0.213 \pm 0.016$ \\
\hline Diabetic $+4 \mathrm{~g} / \mathrm{kg}$ EEM & $7.04 \pm 0.55$ & $5.35 \pm 0.39$ & $2.72 \pm 0.21$ & $0.219 \pm 0.013$ \\
\hline Diabetic $+8 \mathrm{~g} / \mathrm{kg}$ EEM & $7.20 \pm 0.35$ & $5.28 \pm 0.40$ & $2.73 \pm 0.36$ & $0.201 \pm 0.014$ \\
\hline Diabetic + glibenclamide & $7.18 \pm 0.56$ & $5.25 \pm 0.35$ & $2.76 \pm 0.28$ & $0.199 \pm 0.013$ \\
\hline
\end{tabular}

Data are expressed as mean $\pm \mathrm{SD}, n=10$ mice per group. ${ }^{*} P<0.01$ when compared to normal control.

TABLE 4: Effects of repeated EEM administration on glycogen and TG contents in liver and skeletal muscle of normal and diabetic mice.

\begin{tabular}{lcccc}
\hline Group & \multicolumn{2}{c}{ Liver } & \multicolumn{2}{c}{ Skeletal muscle } \\
& Glycogen $(\mathrm{mg} / \mathrm{g})$ & TG $(\mu \mathrm{mol} / \mathrm{g})$ & Glycogen $(\mathrm{mg} / \mathrm{g})$ & $0.126 \pm 0.009$ \\
\hline Normal control & $12.43 \pm 1.19$ & $3.39 \pm 0.28$ & $1.66 \pm 0.16$ & $0.123 \pm 0.007$ \\
Normal + 2 g/kg EEM & $12.36 \pm 1.05$ & $3.45 \pm 0.16$ & $1.55 \pm 0.14$ & $0.131 \pm 0.011$ \\
Normal + 4 g/kg EEM & $12.67 \pm 1.00$ & $3.50 \pm 0.25$ & $1.72 \pm 0.17$ & $0.131 \pm 0.008$ \\
Normal + 8 g/kg EEM & $12.75 \pm 1.33$ & $3.35 \pm 0.27$ & $1.70 \pm 0.15$ & $0.128 \pm 0.007$ \\
Normal + glibenclamide & $12.81 \pm 1.06$ & $3.28 \pm 0.26$ & $2.71 \pm 0.12$ & $0.226 \pm 0.016^{*}$ \\
Diabetic control & $6.86 \pm 0.41^{*}$ & $5.28 \pm 0.21^{*}$ & $2.75 \pm 0.28$ & $0.215 \pm 0.019$ \\
Diabetic + 2 g/kg EEM & $7.28 \pm 0.36$ & $5.29 \pm 0.34$ & $2.04 \pm 0.22^{\#}$ & $0.170 \pm 0.008^{\#}$ \\
Diabetic + 4 g/kg EEM & $9.38 \pm 1.14^{\#}$ & $4.24 \pm 0.37^{\#}$ & $2.03 \pm 0.17^{\#}$ & $0.164 \pm 0.011^{\#}$ \\
Diabetic + 8 g/kg EEM & $9.79 \pm 0.99^{\#}$ & $4.09 \pm 0.30^{\#}$ & $1.79 \pm 0.13^{\#}$ & $0.221 \pm 0.020$ \\
Diabetic + glibenclamide & $10.81 \pm 0.77^{\#}$ & $5.15 \pm 0.33$ & & \\
\hline
\end{tabular}

Data are expressed as mean $\pm \mathrm{SD}, n=10$ mice per group. ${ }^{*} P<0.01$ when compared to normal control. ${ }^{\#} P<0.01$ when compared to diabetic control.

of normal and diabetic mice during 28 days of EEM and glibenclamide administration were shown in Table 4 . In normal mice, once daily administrations of 2,4 , and $8 \mathrm{~g} / \mathrm{kg}$ EEM and glibenclamide for 28 days had no effect on glycogen and TG contents in liver and skeletal muscle. In diabetic mice, glycogen content was significantly lower, and TG content was significantly higher than those of untreated normal mice $(P<0.01)$. Administration of $2 \mathrm{~g} / \mathrm{kg}$ EEM for 28 days did not produce any significant change in glycogen and TG contents in liver and skeletal muscle. However, repeated administration of $4,8 \mathrm{~g} / \mathrm{kg}$ EEM significantly increased glycogen content and reduced TG content in liver and skeletal muscle compared with untreated diabetic mice $(P<$ $0.01)$. Repeated administration of glibenclamide significantly increased glycogen content $(P<0.01)$, but did not affect TG content in liver and skeletal muscle compared with untreated diabetic mice.

3.10. Effects of EEM on the Oral Glucose Tolerance Test. In normal mice, EEM $(4,8 \mathrm{~g} / \mathrm{kg})$ significantly inhibited the increase in blood glucose level after glucose load $(P<0.01)$ (Figure $3(\mathrm{a})$ ), while low dose of EEM $(2 \mathrm{~g} / \mathrm{kg})$ showed no inhibitory effect. In comparative groups, both glibenclamide
$(2.5 \mathrm{mg} / \mathrm{kg})$ and metformin $(50 \mathrm{mg} / \mathrm{kg})$ significantly inhibited the increase in glucose level $(P<0.01)$. In the diabetic mice, EEM $(4,8 \mathrm{~g} / \mathrm{kg})$ also showed significantly inhibitory effect on the increased blood glucose level after glucose load $(P<0.01)$ (Figure $3(\mathrm{~b}))$, while low dose of EEM $(2 \mathrm{~g} / \mathrm{kg})$ did not inhibit the increase in blood glucose level. The inhibitory activities of glibenclamide and metformin were observed after oral glucose load $(P<0.01)$.

When 2, 4, and $8 \mathrm{~g} / \mathrm{kg}$ EEM and glibenclamide were administered for two weeks before induction of diabetes with streptozotocin and for a further 28 days afterwards, essentially similar effects were observed on blood glucose, serum insulin, ISI, serum TC, serum TG, glycogen, and TG contents in liver and skeletal muscle to those seen when EEM and glibenclamide were administered after induction of diabetes (data not shown).

\section{Discussion}

Blood glucose level was increased significantly from the 3rd day in untreated diabetic mice. This increment may be due to reduced glucose clearance apparently arising from a defect in glucose transport [24] and/or to the early appearance in 
insulin resistance in diabetic mice [25]. The experimental diabetic mice used in this study were type 2 diabetic ones because low dose of streptozotocin $(60 \mathrm{mg} / \mathrm{kg})$ destroyed half a population of pancreatic $\beta$ cells and had a high blood glucose level, which are in accord with the results of previous investigations [26, 27]. Single administration EEM had no effect on blood glucose, TC, TG levels and glycogen, and TG contents in liver and skeletal muscle of both normal and diabetic mice. What is more, repeated administration EEM did not affect blood glucose, TC, TG levels and glycogen, and TG contents in liver and skeletal muscle of normal mice. These results suggest that EEM had no hypoglycemic and hypolipidemic effects on normal mice.

When studying a chronic disease such as diabetes, it is more pertinent to test the maintenance of lower blood glucose level with long-term treatment rather than the acute hypoglycemic effect after a single administration. In this study, we found that repeated administration EEM continually decreased blood glucose level in diabetic mice both after and before induction with streptozotocin. In diabetic liver and skeletal muscle, glycogen content was lower and TG content was higher than those of normal mice, which accords with other reports [28], and this phenomenon was related with impaired glucose synthesis in the mouse liver and skeletal muscle during diabetes [29]. Repeated EEM administration significantly increased tissue glycogen content in diabetic mice. In the oral glucose tolerance test, EEM $(4,8 \mathrm{~g} / \mathrm{kg})$ significantly improved hyperglycemia after oral glucose load both in normal and diabetic mice. On the other hand, the higher dose of glibenclamide $(2.5 \mathrm{mg} / \mathrm{kg})$, one of the sulfonylureas that stimulates insulin secretion [30], and metformin, one of the iguanids that inhibits hepatic glucose output [31], improved hyperglycemia after oral glucose load. Two hours after single EEM administration failed to reduce serum insulin level and to improve ISI both in normal and diabetic mice. Repeated EEM administration to diabetic mice decreased serum insulin level and improved ISI, but not for normal mice. The prevention of depletion of glycogen in the liver and skeletal muscle by EEM may be due to improved ISI, but not for stimulation of insulin release from $\beta$ cells.

Several medicinal plants have been reported to restore activity of key enzymes of glucose and glycogen metabolism which are strongly disturbed in streptozotocin-induced diabetic mice [32, 33]. Hypoglycemic activity of EEM may arise from inhibition of hepatic glucose production. Several medicinal plants possess an insulin-sensitizing activity in experimental diabetic mice $[34,35]$. Since streptozotocininduced diabetes is accompanied by insulin resistance, EEM improved insulin sensitivity. It was reported that a traditional herbal medicine improved insulin action in streptozotocininduced diabetic mice via enhancing insulin signaling [36, 37]. So other underlying mechanisms of the blood glucose lowering activity of EEM need further study.

The philosophy behind the medicinal uses of traditional Chinese medicine is holistic in nature, which differs from western medicines, and all chemical components present in a particular traditional Chinese medicine are believed to be of therapeutic importance. It was generally recommended to separate and measure the active chemical ingredients for standardization and quality control of herbal products. What is more, the confirmation of main constituent in herb and herbal extract helps to clarify its pharmacological effects. Previous studies reported that the Mirabilis jalapa L. root contains phytocompounds, such as alkaloids, glycosides, carbohydrates, and phytosterols $[9,17]$. Phytochemical analysis shows that the Mirabilis jalapa L. roots contain plentiful trigonelline. As one of the components of Mirabilis jalapa L. root, trigonelline reduced blood glucose level in animal and human [19-22] and improved glucose tolerance in diabetes with obesity by oral glucose tolerance test. Trigonelline also reduced TC, free plasma cholesterol, and TG levels in the serum, liver, and adipose tissue $[38,39]$. What is more, trigonelline decreased serum insulin, serum tumor necrosis factor $\alpha$ levels, and liver fatty acid synthase activity and increased carnitine palmitoyl transferase, glucokinase activities, and glucokinase/glucose-6-phosphatase ratio in the liver $[38,40]$. Therefore, it was reasonable to suggest that the insulin sensitivity, hypoglycemia, and hypolipidemia profile of EEM might be connected to the existence of the phytocompounds, especially the trigonelline. Meanwhile, our results clearly demonstrate that administration EEM provides beneficial insulin sensitivity, hypoglycemic, and hypolipidemic effects especially on diabetic mice both after and before induction with streptozotocin.

In conclusion, our study demonstrates that Mirabilis jalapa L. root can be used to treat type 2 diabetes with hyperlipidemia. Mirabilis jalapa L. root may be developed as an oral hypoglycemic agent or functional food for diabetic patients with hyperlipidemia and for persons with high risk of diabetes. This finding represents an experimental confirmation of the Chinese traditional use of this plant for diabetic treatment. Consequently, consumption of Mirabilis jalapa L. root may prevent the complication of hyperglycemia associated with diabetes. Finally, the precise mechanism(s) and site(s) of this activity and the active constituent(s) of Mirabilis jalapa L. root still need to be determined in addition to toxicological studies in further experiments.

\section{Acknowledgments}

The auhors gratefully acknowledge the fundings from the National Natural Science Foundation of China (no. 81100597), Natural Science Foundation Project of Chongqing Science and Technology Commission (no. CSTC 2009BA5012), and the Natural Science Foundation of Third Military Medical University (no. 2009XQN34).

\section{References}

[1] P. E. Cryer, "The barrier of hypoglycemia in diabetes," Diabetes, vol. 57, no. 12, pp. 3169-3176, 2008.

[2] T. Shimada, M. Kosugi, D. Tokuhara et al., "Preventive effect of pine bark extract (Flavangenol) on metabolic disease in western diet-loaded tsumura suzuki obese diabetes mice," Evidence-Based Complementary and Alternative Medicine, vol. 2011, Article ID 185913, 9 pages, 2011. 
[3] S. Ghosh, M. Ahire, S. Patil et al., "Antidiabetic activity of Gnidia glauca and Dioscorea bulbifera: potent amylase and glucosidase inhibitors," Evidence-Based Complementary and Alternative Medicine, vol. 2012, Article ID 929051, 10 pages, 2012.

[4] A. Benhaddou-Andaloussi, L. Martineau, T. Vuong et al., "The in vivo antidiabetic activity of Nigella sativa is mediated through activation of the AMPK pathway and increased muscle Glut4 content," Evidence-Based Complementary and Alternative Medicine, vol. 2011, Article ID 538671, 9 pages, 2011.

[5] A. C. Leite, T. G. Araújo, B. D.M. Carvalho, M. B.S. Maia, and V. L.D.M. Lima, "Characterization of the antidiabetic role of Parkinsonia aculeata (Caesalpineaceae)," Evidence-Based Complementary and Alternative Medicine, vol. 2011, Article ID 692378, 9 pages, 2011.

[6] A. Al-Aboudi and F. U. Afifi, "Plants used for the treatment of diabetes in Jordan: a review of scientific evidence," Pharmaceutical Biology, vol. 49, no. 3, pp. 221-239, 2011.

[7] R. Encarnación Dimayuga, M. Virgen, and N. Ochoa, "Antimicrobial activity of medicinal plants from Baja California Sur (Mexico)," Pharmaceutical Biology, vol. 36, no. 1, pp. 33-43, 1998.

[8] D. K. Holdsworth, "A preliminary study of medicinal plants of Easter Island, South Pacific," International Journal of Pharmacognosy, vol. 30, no. 1, pp. 27-32, 1992.

[9] C. I. B. Walker, G. Trevisan, M. F. Rossato et al., "Antinociceptive activity of Mirabilis jalapa in mice," Journal of Ethnopharmacology, vol. 120, no. 2, pp. 169-175, 2008.

[10] C. Kusamba, K. Byamana, and W. M. Mbuyi, "Antibacterial activity of Mirabilis jalapa seed powder," Journal of Ethnopharmacology, vol. 35, no. 2, pp. 197-199, 1991.

[11] M. F. C. De Bolle, R. W. Osborn, I. J. Goderis et al., "Antimicrobial peptides from Mirabilis jalapa and Amaranthus caudatus: expression, processing, localization and biological activity in transgenic tobacco," Plant Molecular Biology, vol. 31, no. 5, pp. 993-1008, 1996.

[12] J. M. Vivanco, M. Querci, and L. F. Salazar, "Antiviral and antiviroid activity of MAP-containing extracts from Mirabilis jalapa roots," Plant Disease, vol. 83, no. 12, pp. 1116-1121, 1999.

[13] State Administration of Traditional Chinese Medicine, "Chinese materia medica," in Editorial Board, Chinese Materia Medica (II), pp. 748-749, Shanghai Science and Technology Press, Shanghai, China, 1999.

[14] Jiangsu New Medical College, The Second Volume of Dictionary of Chinese Medicine, Shanghai People's Publishing House, Shanghai, China, 1977.

[15] S. Lee, C. Xiao, and S. Pei, "Ethnobotanical survey of medicinal plants at periodic markets of Honghe Prefecture in Yunnan Province, SW China," Journal of Ethnopharmacology, vol. 117, no. 2, pp. 362-377, 2008.

[16] C. S. Weckerle, R. Ineichen, F. K. Huber, and Y. Yang, "Mao's heritage: medicinal plant knowledge among the Bai in Shaxi, China, at a crossroads between distinct local and common widespread practice," Journal of Ethnopharmacology, vol. 123, no. 2, pp. 213-228, 2009.

[17] S. Piyali, K. M. Abdul, and P. M. Jyochhna, "Antidiabetic activity of ethanolic extract of Mirabilis jalapa roots," International Journal of Pharmacy and Technology, vol. 3, no. 1, pp. 14701479, 2011.

[18] F. Y. Song, D. Z. Zhang, Y. X. Zhong, W. Wang, and S. H. Zeng, "Content determination of trigonelline in Radix Mirabilis by RP-HPLC," Traditional Chinese Drug Research \& Clinical Pharmacology, vol. 16, no. 3, pp. 189-191, 2005.

[19] R. Moorthy, K. Prabhu, and P. Murthy, "Studies on the isolation and effect of an orally active hypoglycaemic principle from the seeds of fenugreek (Trigonella foenum-graecum)," Diabetes Bulletin, vol. 9, pp. 69-72, 1989.

[20] J. Mishkinsky, B. Joseph, and F. G. Sulman, "Hypoglycaemic effect of trigonelline," The Lancet, vol. 2, no. 7529, pp. 13111312, 1967.

[21] A. E. Van Dijk, M. R. Olthof, J. C. Meeuse, E. Seebus, R. J. Heine, and R. M. Van Dam, "Acute effects of decaffeinated coffee and the major coffee components chlorogenic acid and trigonelline on glucose tolerance," Diabetes Care, vol. 32, no. 6, pp. 1023-1025, 2009.

[22] M. R. Olthof, A. E. Van Dijk, C. F. Deacon, R. J. Heine, and R. M. Van Dam, "Acute effects of decaffeinated coffee and the major coffee components chlorogenic acid and trigonelline on incretin hormones," Nutrition and Metabolism, vol. 8, p. 10, 2011.

[23] X. Hu, Y. Feng, Y. Shen et al., "Antidiabetic effect of a novel non-thiazolidinedione PPAR $\gamma / \alpha$ agonist on ob/ob mice," Acta Pharmacologica Sinica, vol. 27, no. 10, pp. 1346-1352, 2006.

[24] J. K. Wi, J. K. Kim, and J. H. Youn, "Reduced glucose clearance as the major determinant of postabsorptive hyperglycemia in diabetic rats," American Journal of Physiology, vol. 274, no. 2, pp. E257-E264, 1998.

[25] O. Blondel and B. Portha, "Early appearance of in vivo insulin resistance in adult spreptozotocin-injected rats," Diabete et Metabolisme, vol. 15, no. 6, pp. 382-387, 1989.

[26] L. Wang, X. T. Zhang, H. Y. Zhang, H. Y. Yao, and H. Zhang, "Effect of Vaccinium bracteatum Thunb. leaves extract on blood glucose and plasma lipid levels in streptozotocininduced diabetic mice," Journal of Ethnopharmacology, vol. 130, no. 3, pp. 465-469, 2010.

[27] S. H. Lee, M. H. Park, S. J. Heo et al., "Dieckol isolated from Ecklonia cava inhibits $\alpha$-glucosidase and $\alpha$-amylase in vitro and alleviates postprandial hyperglycemia in streptozotocininduced diabetic mice," Food and Chemical Toxicology, vol. 48, no. 10, pp. 2633-2637, 2010.

[28] P. Pandikumar, N. P. Babu, and S. Ignacimuthu, "Hypoglycemic and antihyperglycemic effect of Begonia malabarica Lam. in normal and streptozotocin induced diabetic rats," Journal of Ethnopharmacology, vol. 124, no. 1, pp. 111-115, 2009.

[29] D. F. Hwang, Y. S. Lai, and M. T. Chiang, "Toxic effects of grass carp, snake and chicken bile juices in rats," Toxicology Letters, vol. 85, no. 2, pp. 85-95, 1996.

[30] J. M. Feldman, "Glyburide: a second-generation sulfonylurea hypoglycemic agent. History, chemistry, metabolism, pharmacokinetics, clinical use and adverse effects," Pharmacotherapy, vol. 5, no. 2, pp. 43-62, 1985.

[31] R. K. Campbell, J. R. White Jr., and B. A. Saulie, "Metformin: a new oral biguanide," Clinical Therapeutics, vol. 18, no. 3, pp. 360-371, 1996.

[32] M. Eddouks, H. Jouad, M. Maghrani, A. Lemhadri, and R. Burcelin, "Inhibition of endogenous glucose production accounts for hypoglycemic effect of Spergularia purpurea in streptozotocin mice," Phytomedicine, vol. 10, no. 6-7, pp. 594599, 2003.

[33] B. Sharma, R. Salunke, C. Balomajumder, S. Daniel, and P. Roy, "Anti-diabetic potential of alkaloid rich fraction from Capparis decidua on diabetic mice," Journal of Ethnopharmacology, vol. 127, no. 2, pp. 457-462, 2010. 
[34] A. S. Attele, Y. P. Zhou, J. T. Xie et al., "Antidiabetic effects of Panax ginseng berry extract and the identification of an effective component," Diabetes, vol. 51, no. 6, pp. 1851-1858, 2002.

[35] M. Liu, K. Wu, X. Mao, Y. Wu, and J. Ouyang, "Astragalus polysaccharide improves insulin sensitivity in KKAy mice: regulation of PKB/GLUT4 signaling in skeletal muscle," Journal of Ethnopharmacology, vol. 127, no. 1, pp. 32-37, 2010.

[36] B. Qin, M. Nagasaki, M. Ren, G. Bajotto, Y. Oshida, and Y. Sato, "Effects of Keishi-ka-jutsubu-to (traditional herbal medicine: Gui-zhi-jia-shu-fu-tang) on in vivo insulin action in streptozotocin-induced diabetic rats," Life Sciences, vol. 73, no. 21, pp. 2687-2701, 2003.

[37] B. Qin, M. Nagasaki, M. Ren, G. Bajotto, Y. Oshida, and Y. Sato, "Cinnamon extract (traditional herb) potentiates in vivo insulin-regulated glucose utilization via enhancing insulin signaling in rats," Diabetes Research and Clinical Practice, vol. 62, no. 3, pp. 139-148, 2003.

[38] O. Yoshinari and K. Igarashi, "Anti-diabetic effect of trigonelline and nicotinic acid, on KK-A ${ }^{y}$ mice," Current Medicinal Chemistry, vol. 17, no. 20, pp. 2196-2202, 2010.

[39] S. Abe and T. Kaneda, "Effect of betaines and taurine and its derivatives on plasma cholesterol levels in rats," Eiyo To Shokuryo, vol. 28, no. 3, pp. 125-128, 1975.

[40] O. Yoshinari, H. Sato, and K. Igarashi, "Anti-diabetic effects of pumpkin and its components, trigonelline and nicotinic acid, on goto-kakizaki rats," Bioscience, Biotechnology and Biochemistry, vol. 73, no. 5, pp. 1033-1041, 2009. 


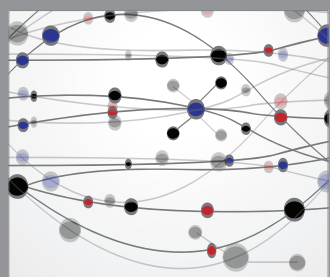

The Scientific World Journal
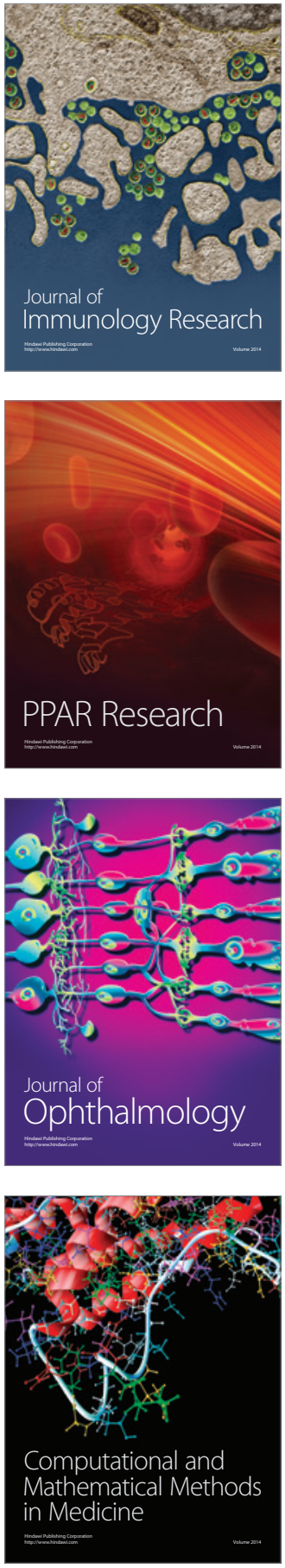

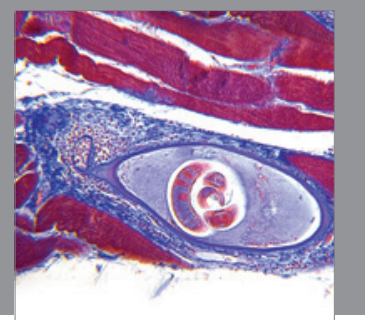

Gastroenterology

Research and Practice
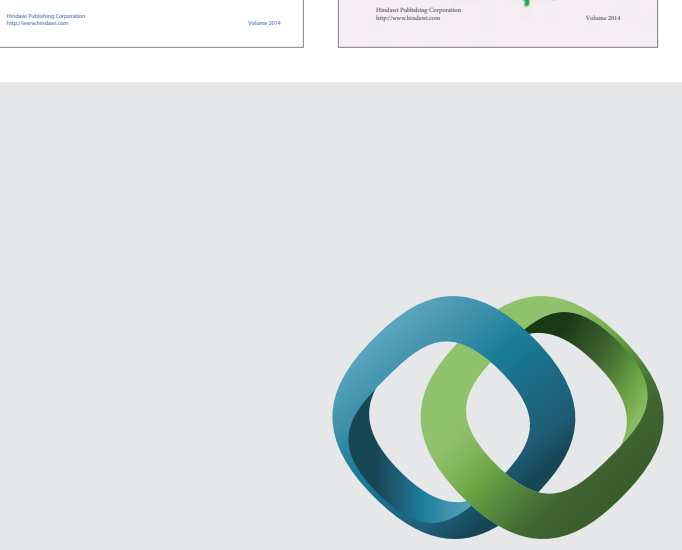

\section{Hindawi}

Submit your manuscripts at

http://www.hindawi.com
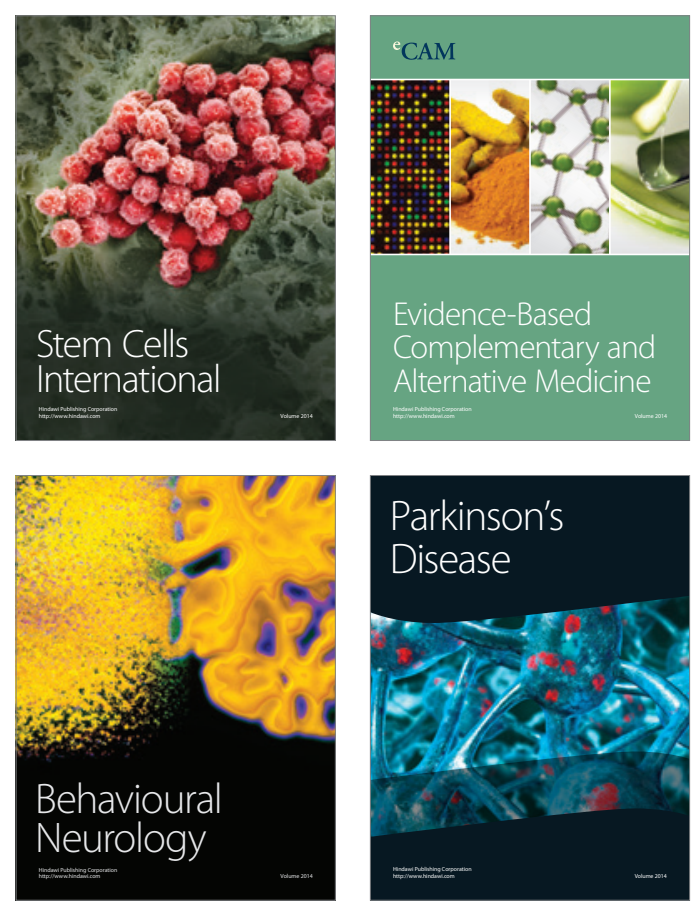

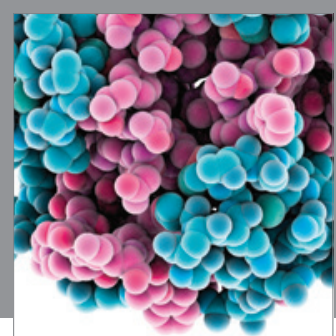

Journal of
Diabetes Research

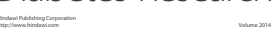

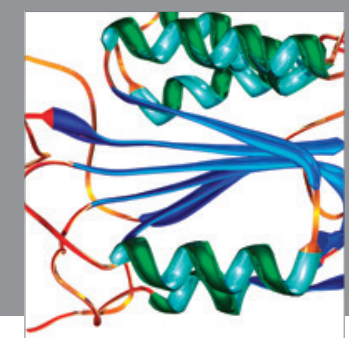

Disease Markers
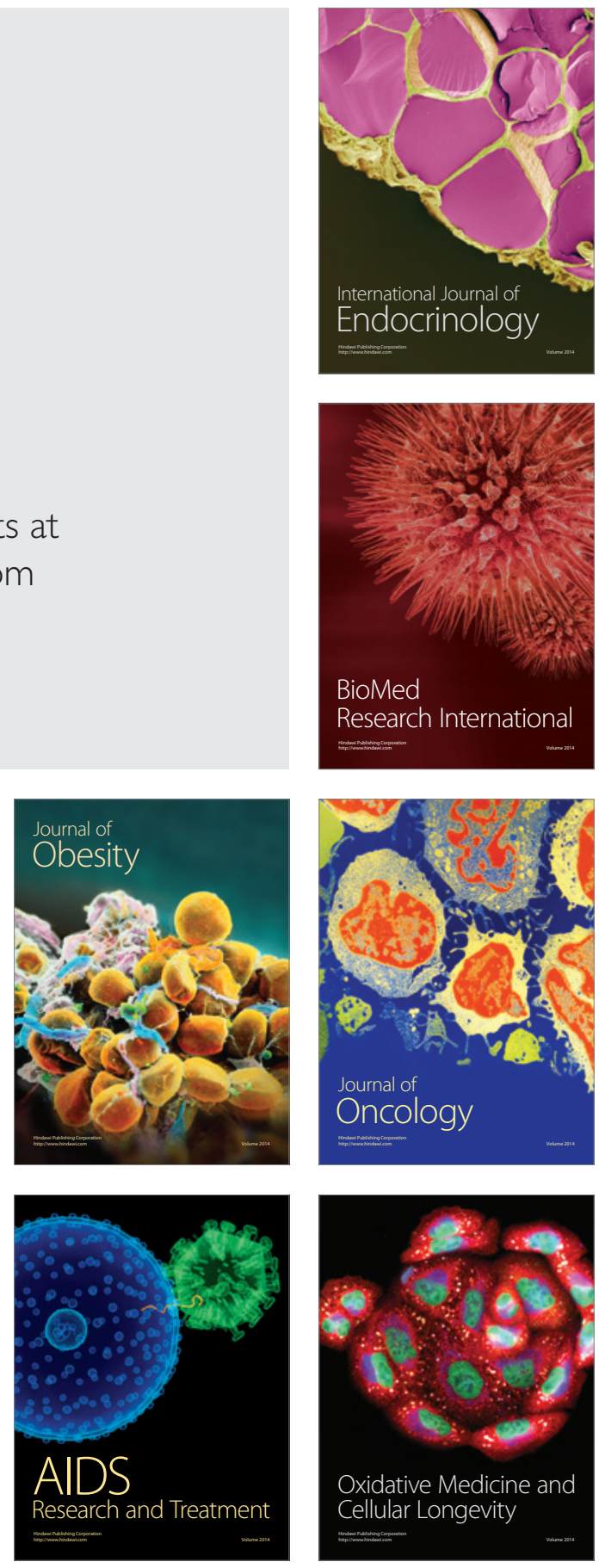